Series editor: David Taylor

\section{I went; I saw: I was never the same!}

\section{Richard Bowman}

\section{Time spent training in developing countries}

A s our small plane approached Kismayu airport, Somalia, my more experienced colleague lent forward to the pilot and said "if they start shooting at us, turn back." They didn't but, when we landed, the plane was quickly surrounded by angry looking, young Somalis bearing Kalashnikovs. It was then I realised that Casualty at Moorfields wasn't so bad after all. A shouting match developed between their leader and the Médecins Sans Frontières escort sent to meet us, in Somaliunfortunately my Somali is not all it should be. The shouting got louder and louder and I got tenser and tenser, until suddenly huge smiles broke out and the leader thumped my colleague on the back: "Don't worry he said" grinning "Shouting is part of our culture."

That trip was part of a three month placement in the eye unit of the Christoffel Blindenmission (CBM) supported Presbyterian church hospital at Kikuyu, Nairobi, in Kenya, which I undertook during my second year of specialist registrar (SpR) training. Later I spent a further two years (out of SpR training) doing a research fellowship based at the International Centre for Eye Health (ICEH) and sponsored by Sight Savers International, which involved living and working in the Gambia, west Africa, for 18 months, conducting operational research on trachoma control. I became involved with these projects because I have an interest in working in developing countries in the longer term, but even for trainees who intend to concentrate their career in the United Kingdom there are definite benefits available from spending some period of their training abroad.

In 1995, the NHS executive wrote to trusts and health authorities alerting them to the opportunities of overseas experience for NHS staff. ${ }^{1}$ The royal colleges seem to be in general agreement that doctors can benefit from being part of a well structured overseas programme. Specific areas of professional development enhancement that have been cited include empathy, accelerated clinical learning, a cost conscious approach to health care, taking responsibility for developing quality of care, and flexibility. ${ }^{2}$ What might be the specific benefits for the ophthalmic trainee?

Firstly, it contributes to our general and moral education: it broadens our cultural perspective. Most cross cultural lessons are less nerve racking than the example above! Most ophthalmologists are aware of the worldwide statistics on blindness from cataract (even if we can't remember the number, we know it is a lot). However, there is no substitute for first hand experience of attempting to chip away (not literally) at the global problem of cataract blindness, with limited resources, and seeing the faces of those affected both before and after surgery.

Secondly, there is an exciting wealth of pathology presenting clinical and surgical challenges. In three months at Kikuyu, I performed more than 20 repairs of penetrating injuries and about 10 corneal grafts. No one advocates sending inexperienced junior surgeons to developing countries for unsupervised surgical practice but, as at Kikuyu when I was there, experienced skilled consultants are available and keen to teach. This, combined with the huge variety and volume of cases, presents a valuable training resource. It is right that this resource is primarily directed at local national trainees, but there are still opportunities for UK trainees to benefit and contribute.

\section{Involvement in projects in developing countries often results in exposure to health service management and planning, prioritising resource allocation, and team leadership}

Thirdly, involvement in projects in developing countries often results in exposure to health service management and planning, prioritising resource allocation, and team leadership. Experience and skill in these areas are in increasing demand in the 21 st century NHS and may be difficult to acquire as a junior doctor in the United Kingdom. At one specialist registrar interview, I was asked what management experience I had. The previous week I had been in Ghana for a two day national trachoma programme planning meeting. Present at the meeting had been government ministers, health service managers, medical and nursing staff, non-governmental organisation (NGO) and World Health Organization (WHO) representatives. The agenda covered priority setting, aims, organisational structure, cross specialty collaboration, resource allocation, audit, and operational research requirements culminating in an action plan with a time scale. Experiences like these, apart from being valuable in their own right, may help an interview candidate stand out

Some aspects of the development areas of eye care services in poorer countries may be ahead of those in the West. An obvious example is the increasing responsibility now given to nurses in the NHS (for example, nurse led clinics, assessment of postoperative cases and, controversially, the possibility of nurses performing surgery). Such responsibilities have long been undertaken by ophthalmic nurses in Africa where there is on average only one ophthalmologist per million of the population compared to 12 per million in the United Kingdom and 50 in some parts of Europe. Therefore, ophthalmologists who have worked in Africa may understand the possibilities and limitations of the extended nurse role.

Fourthly, and finally, there are excellent opportunities for research work. It is an unfortunate fact that although developing countries bear the burden of $90 \%$ of global disease, only $10 \%$ of global expenditure on medical research is directed towards this burden': this inequity represents an exciting and potentially rewarding challenge. The ICEH (a WHO collaborating centre) has had a long tradition of offering NGO funded research fellowships covering a wide range of subjects and geographic locations. Currently, four of the SpRs on the North Thames training rotation in London alone have benefited from these, either before starting or during their specialist training period. Epidemiology is often a central part of such research projects, though opportunities for basic science also exist. Epidemiology is another skill that is in relatively short supply in ophthalmology, and yet can be of great use when returning to clinical work in terms of assessing need and planning services accordingly. Ethical issues surrounding research in developing countries have received recent attention and the importance of local "national ownership" of projects emphasised. ${ }^{3}$ In practice, this means integration and collaboration with local research bodies, where possible, about the subject and the design of the research as well as logistics. Models of research projects that involve skill transfer to local staff and capacity building have been proposed as preferable to those in which a UK trainee is "parachuted" in for fieldwork only to leave as quickly as possible with samples or data for analysis in the United Kingdom. ${ }^{4}$ 
When is the best time to go? No units in developing countries are currently accredited for higher surgical training though some in India are accredited for basic surgical training (S Cook, director of training, Royal College of Ophthalmologists, personal communication). In practice, senior house officers are probably too busy with examinations and learning basic clinical and surgical skills to venture abroad for long. Times that are more suitable are before or during a specialist registrar post. One advantage of "Calmanised" training (the current UK training scheme) is that it is possible to retain a training number while engaging in a deanery approved research project-this allows a degree of flexibility in timing a project. Six months may be allowed to count towards the period of higher surgical training but prior agreement from the college should be sought if this is desired.

Should there be more recognition of these benefits from the college and perhaps more active encouragement and organisational support for trainees wishing to gain overseas experience? The Royal College of Paediatricians has pioneered an innovative link with Voluntary
Services Overseas (VSO) that has also been approved in principle by the Royal College of Obstetricians and Gynaecologists. ${ }^{5}$ Similar initiatives could be explored with the SightSavers and CBM working in blindness prevention. The Royal College of Physicians is developing an exchange scheme with the Hong Kong College of Medicine. ${ }^{5} \mathrm{Al}-$ though exchange schemes may be more difficult with developing countries, once formalised training programmes are established and approved they become a possibility. Exchange programmes have potential benefit for trainees from both the United Kingdom and from developing countries and leave neither programme depleted of staff.

In conclusion, spending time in developing countries while training as an ophthalmologist is personally and professionally rewarding and, providing you are ready for the unexpected, exciting. You may acquire experience and skills that are in short supply among UK trainees, that will benefit your professional development, and that may help you stand out from a competitive field. On the other hand, you may decide never to come back!

\section{ACKNOWLEDGEMENTS}

I would like to thank Allen Foster, David Yorston, Gordon Johnson, Hannah Faal, and Robin Bailey for their personal support and encouragement in this area. I would also like to thank the consultant staff in Cambridge, Glasgow, Moorfields, and Great Ormond Street for their support and in allowing me to take time out from training.

Br J Ophthalmol 2002;86:370-371

\section{Author's affiliations}

R Bowman, Ophthalmology Department, Great Ormond Street Hospital, London WCIN 3JH,

UK

\section{REFERENCES}

1 NHS Executive. Overseas work and professional development. (EL9569) Leeds: NHSE, 1995

2 Banatvala N, Macklow-Smith A. Integrating overseas work with and NHS career. http:/bmi.com//cgi/content/full/3 14/7093/ S2-s7093.

3 Kitua AY, Mashalla YJ, Shija JK. Coordinating health research to promote action: the Tanzanian experience. BM 2000;321:821-3.

4 Costello A, Zumala A. Moving to research partnerships in developing countries. BM 2000;321:827-9.

5 Banatvala N, Scott I. Working overseas: from individual to organisational strategy. http:/bmj.com//cgi/content/full/323/7315/ S2-7315.

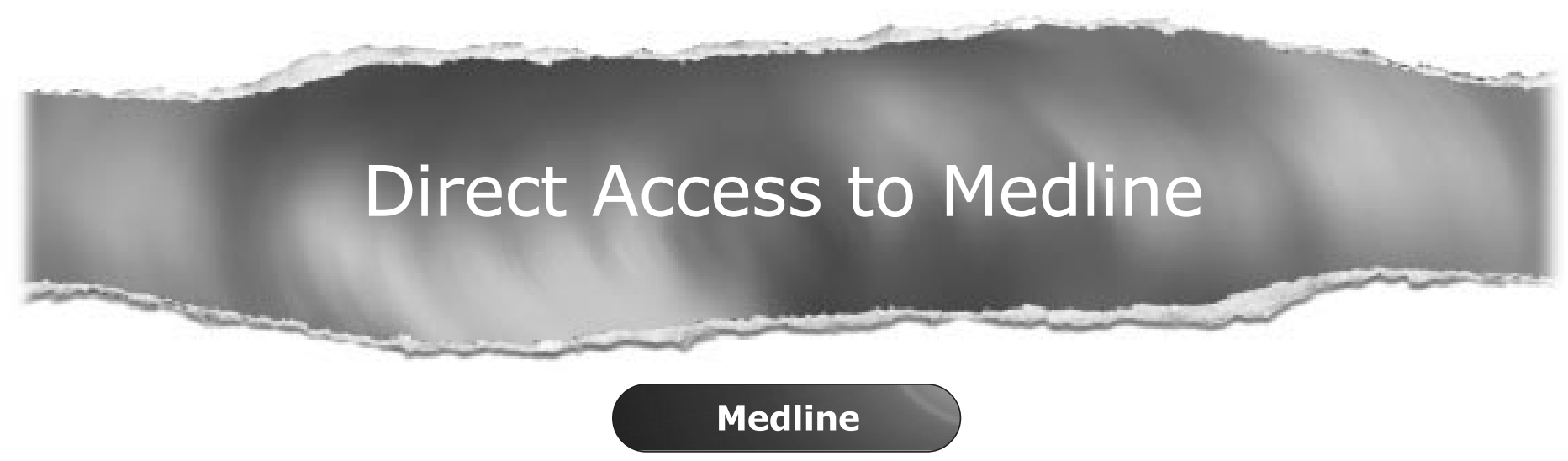

Link to Medline from the homepage and get straight into the National Library of Medicine's premier bibliographic database. Medline allows you to search across 9 million records of bibliographic citations and author abstracts from approximately 3,900 current biomedical journals.

www.bjophthalmol.com 